\title{
Optimalisasi Penempatan UPFC Pada Sistem Jawa Bali 500kv Menggunakan Algoritma Genetika
}

\author{
Danu Firmansyah $^{1}$ dan Istiyo Winarno ${ }^{2}$ \\ 1,2)Fakultas Teknik dan Ilmu Kelautan, Universitas \\ Hang Tuah Surabaya
}

\begin{abstract}
Abstrak-. Jaringan transmisi merupakan bagian penting dalam sistem tenaga untuk menyalurkan energi listrik dari pusat pembangkit ke beban, untuk itu sistem tenaga harus diusahakan secara maksimal agar dicapai aliran daya yang optimal, Unified Power Flow Control (UPFC) adalah salah satu perangkat Flexible AC TransmissionSystem (FACTS) yang mampu mengendalikan daya saluran transmisi secara terpisah pada transmisi listrik dan dapat dipasang pada ujung pengirim maupun penerima daya. Model injeksi daya UPFC ke saluran transmisi dibuat dalam suatu persamaan aliran daya Pada sistem Jawa Bali (Jali) $500 \mathrm{kV}$ yang dianalisis dengan metode Algoritma Genetika,agar menghasilkan injeksi daya yang dapat meminimalisasi rugi daya aktif dan reaktif saluran transmisi tanpa melampaui batas perangkat UPFC. Pada sistem Jawa Bali (Jali) 500 kV yang dianalisis dengan metode Algoritma Genetika,nilai UPFC yang optimalDaya Reaktif yang diinjeksikan pada sistem untuk bus 39 sebesar 9695.593207 MVar, bus 15 sebesar 10598.78754 MVar, dan pada bus 37 sebesar 10755.88608 MVar. Total rugi - rugi daya saluran pada sistem sebelum dipasang UPFC adalah 1815.775809 MW, sedangkan total rugi - rugi daya saluran pada sistem sesudah dipasang UPFC dengan GA adalah 1537.391648 MW.
\end{abstract}

Kata kunci :UPFC, injeksi daya, Algoritma Genetika, aliran daya saluran transmisi

Abstrak-. The transmission network is an important part of the power system to deliver electrical energy from the power plant to the load, therefore the power system must be maximized to achieve optimal power flow, Unified Power Flow Control (UPFC) is one of the Flexible AC Transmission System (FACTS ) capable of controlling the power of the transmission line separately on electrical transmission and can be mounted on both the sender and the receiving end of the power. The UPFC power injection model to the transmission line is made in a power flow equation. In

\author{
Jalan Arif Rahman Hakim No. 150, Keputih-Sukolilo, \\ Surabaya 60111 \\ Email : danufirmansyah8@gmail.com
}

the Java Bali (Jali) $500 \mathrm{kV}$ system analyzed by the Genetic Algorithm method, to produce a power injection that minimizes the active and reactive power losses of the transmission line without exceeding the UPFC device limit. In the Java Bali (Jali) 500 kV system analyzed by Genetic Algorithm method, the optimum UPFC value of Reactive Power injected to the system for bus 39 is 9695.593207MVar, bus 15 is 10598.78754 MVar, and on bus 37 is10755.88608 MVar. The total loss of channel power on the system prior to installation of UPFC is1815.775809 MW, while the total loss of channel power in the system after installing UPFC with GA is1537.391648 MW.

Keywords: UPFC, power injection, Genetic Algorithm, transmission line power flow

\section{PENDAHULUAN}

Pertumbuhan industri dan jumlah penduduk di indonesia menyebabkan kebutuhan daya listrik meningkat. Kebutuhan daya listrik tersebut dipenuhi dengan menambah pusat pembangkit listrik dan meningkatkan kapasitas transmisi daya listrik. Peningkatan kapasitas transmisi daya listrik dengan cara membangun saluran transmisi baru, tentunya membutuhkan biaya investasi yang tinggi dan menimbulkan masalah sosial yang sulit ditangani. Pertumbuhan beban industri yang didominasi beban induktif membutuhkan suplai daya reaktif yang cukup besar. Kebutuhan daya reaktif ini tentunya akan menurunkan available power yang dapat ditransmisikan ke beban. Oleh karena itu perlu dilakukan pengaturan aliran daya aktif dan reaktif pada saluran transmisi sehingga dicapai proses penyaluran daya yang efisien.

Aliran daya reaktif pada saluran transmisi akan menurunkan kapasitas penyaluran daya aktif yang dibutuhkan beban. Namun daya reaktif ini juga merupakan komponen penting dalam stabilitas sistem tenaga listrik. Untuk itu, aliran daya aktif dan reaktif dalam saluran transmisi perlu diatur sehingga kapasitas 


\section{$\pi[T]$ Journal of Electrical and Electronic Engineering Vol. 2, No. 1, April 2018}

dan kestabilan sistem transmisi tenaga listrik tetap terjaga. Salah satu perangkat FACTS yang mampu mengendalikan aliran daya saluran transmisi adalah Pengendali Aliran Daya Terpadu (Unified

Power Flow Control / UPFC). Perangkat UPFC terdiri dari converter shunt dan converter seri sebagai sumber tegangan injeksi yang terhubung secara bersama dengan kapasitor penyimpanan tegangan searah. Prinsip kerja UPFC yaitu konverter 2 sebagai fungsi utama UPFC untuk menginjeksikan tegangan sebesar Vpq dengan magnitude Vpq dan sudut phasa yang dapat dikendalikan seri dengan saluran transmisi melalui exciting transformer. Perangkat UPFC dapat memberikan kebutuhan fungsional yang mudah disesuaikan untuk kendali aliran daya optimal.

Algoritma Genetika merupakan metoda adaptive yang biasa digunakan untuk pencarian nilai dalam sebuah masalah optimisasi (minimasi atau maksimasi) yang mempunyai banyak sekali solusi yang mungkin (feasible solution).Pada penelitian ini algoritma genetika digunakan untuk mencari nilai optimal penempatan UPFC.

Pada sistem Jawa Bali (Jali) $500 \mathrm{kV}$ yang dianalisis dengan metode Algoritma Genetika, nilai UPFC yang optimal Daya Reaktif yang diinjeksikan pada sistem untuk bus 39 sebesar 9695.593207

MVar, bus 15 sebesar 10598.78754 MVar, dan pada bus 37 sebesar 10755.88608 MVar. Total rugi - rugi daya saluran pada sistem sebelum dipasang UPFC adalah 1815.775809 MW, sedangkan total rugi - rugi daya saluran pada sistem sesudah dipasang UPFC dengan GA adalah 1537.391648 MW.

\section{TINJAUAN PUSTAKA}

\subsection{Saluran Transmisi}

Untuk menyalurkan energi listrik dari pusat pembangkit listrik ke pusat beban, maka energi listrik disalurkan melalui saluran transmisi tegangan dari generator dinaikkan ketingkat tegangan transmisi, yaitu antara $30 \mathrm{kV}$ sampai $500 \mathrm{kV}$ dengan menggunakan transformator penaik tegangan. Dengan tegangan tinggi selain memperbesar daya hantar dari saluran, juga memperkecil rugi - rugi daya dan drop voltage pada tegangan pada saluran penurunan tegangan dari tegangan transmisi dilakukan di gardu induk, di mana tegangan di turunkan ke tingkat yang lebih rendah, yaitu : $500 \mathrm{kV}$ ke $150 \mathrm{kV}$ atau $150 \mathrm{kV}$ ke $70 \mathrm{kV}$. Setelah itu dilakukan penurunan kedua pada gardu induk distribusi yaitu dari $150 \mathrm{kV}$ ke $20 \mathrm{kV}$ atau $70 \mathrm{kV}$ ke 20 $\mathrm{kV}$. Tegangan $20 \mathrm{kV}$ ini disebut tegangan distribusi primer. Tegangan $20 \mathrm{kV}$ ini nantinya akan didistribusikan ke konsumen dan diturunkan lagi di gardu tiang dari $20 \mathrm{kV}$ ke $380 \mathrm{~V}$. Tegangan $380 \mathrm{~V}$ ini disebut dengan tegangan distribusi sekunder. Terdapat 2 kategori saluran transmisi : saluran udara (overhead lines) dan saluran kabel tanah(underground cable).

Saluran udara menyalurkan tenaga listrik melalui kawat - kawat yang digantung pada tiang transmisi dengan perantara isolator - isolator, sedangkan saluran kabel tanah menyalurkan tenaga listrik melalui kabel - kabel yang ditanam dibawah permukaan tanah.

\subsection{Peralatan FACTS ( Flexible AC Transmision System)}

Pengendalian sistem daya listrik bolak balik (AC) telah dikenal sebagai hal yang kompleks. Ini disebabkan oleh perubahan secara terus menerus antara medan magnit dan medan listrik. Bergeraknya arus listrik pada satu transmisi tidak hanya dipengaruhi oleh keberadaan tahanan tetapi juga dari induktansi dan kapasitansi di sepanjang transmisi tersebut. Kombinasi dari ketiga hal inilah yang dikenal dengan istilah impedansi. Selain daripada itu, pada jaringan transmisi listrik AC, daya listrik mengalir dari ujung transmisi dengan voltase fasa leading ke ujung yang lain yang bervoltase fasa tertinggal (lagging).

Besarnya daya listrik yang mengalir pada suatu transmisi akan bertambah dengan semakin besarnya perbedaan sudut fasa antara kedua voltase tersebut. Konsekuensinya, penambahan aliran daya listrik suatu transmisi dengan demikian dapat dilakukan dengan tiga cara: menaikan voltase, menambah selisih sudut antara dua ujung transmisi atau dengan pengurangan impedansi dari transmisi. Teknologi FACTS inilah yang kemudian dikembangkan dengan salah satu tujuan untuk menyediakan peralatan yang fleksible dalam pengaturan atau pengendalian ketiga parameter aliran daya listrik tersebut.

Tabel 1. Hasil Running pada GA

\begin{tabular}{|l|l|l|}
\hline \multicolumn{3}{|l|}{ Final Point } \\
\hline $\mathbf{X}(\mathbf{1})$ & $\mathbf{X}(\mathbf{2})$ & $\mathbf{X}(\mathbf{3})$ \\
\hline 0,845 & 1,369 & 1,318 \\
\hline
\end{tabular}

Tabel diatas menunjukkan hasil dari GA dengan fungsi objektif sesuai dengan persamaan Hasil dari running berupa 3 nilai Bupfc (susceptansi UPFC) masing masing bus yang sensitif tersebut. Running GA ini menggunakan 3 variabel, dimana variable pertama (X1) menunjukkan Bupfc bus 39, variabel kedua (X2) menunjukkan Bupfc bus 15, dan variabel ketiga (X3) menunjukkan Bupfe bus 37.

\subsubsection{Perhitungan Nilai UPFC}

Setelah diketahui nilai Bupfc (susceptansi 


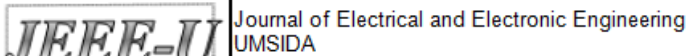 \\ SSN 2460-9250 (print), ISSN 2540-8658 (online) Vol. 2, No. 1, April 2018}

UPFC), untuk mencari nilai UPFC, digunakan perhitungan manual dengan cara mencari daya reaktif UPFC (Qupfc). Untuk mengetahui hasil dari pencarian daya reaktif digunakan persamaan

yang telah dijelaskan pada program matlab. Berikut adalah hasil dari perhitungan Qupfc.

Tabel 2 Hasil Perhitungan Qupfc

\begin{tabular}{|l|l|}
\hline Bus & Nilai Daya Reaktif \\
\hline Bus 39 & $1562 \mathrm{Mvar}$ \\
\hline Bus 15 & $1515 \mathrm{Mvar}$ \\
\hline Bus 37 & $1477 \mathrm{Mvar}$ \\
\hline
\end{tabular}

Tabel 2. menunjukkan hasil perhitungan manual masing - masing daya reaktif bus yang sensitif. Hasil nilai daya reaktif pada tabel 2 dimasukkan ke dalam system interkoneksi Jawa Bali 500 kV. Hasil dimasukkan ke dalam masing - masing bus sesuai dengan variabel yang ditentukan.

\subsubsection{Pengujian Loadflow dan Rugi - Rugi Daya}

Setelah nilai UPFC didapat dan dimasukkan ke sistem, akan dilakukan pengujiankembali loadflow untuk melihat kestabilan tegangan Hasil dari loadflow ditunjukkan pada tabel 3. dibawah ini.

Tabel 3 Hasil loadflow setelah ada UPFC

\begin{tabular}{|c|c|c|c|c|}
\hline No & Nama Bus & $\begin{array}{c}\text { Nominal } \\
\text { (KV) }\end{array}$ & $\begin{array}{c}\text { Tegangan } \\
\text { (PU) }\end{array}$ & $\begin{array}{c}\text { Tegangan } \\
\text { (KV) }\end{array}$ \\
\hline 1 & SURALAYA & 500 & 0.0006559 & 499.5951401 \\
\hline 2 & CIIEOON & 500 & 0.0001937 & 499.9583063 \\
\hline 3 & BANTEN & 500 & 0.845 & 499.155 \\
\hline 4 & BOJANEGARA & 500 & 0.802 & 459.198 \\
\hline 5 & BALARAA & 500 & $5.17 \mathrm{E} \cdot 05$ & 499.9999484 \\
\hline 6 & LENGKONG & 500 & $2.45 E-19$ & 500 \\
\hline 7 & GANDUL & 500 & $3.20 \mathrm{E}-09$ & 500 \\
\hline 8 & KEMBANOAN & 500 & $3.06 \mathrm{E}-09$ & 500 \\
\hline 9 & DURIKOSAMABI & 500 & $4.02 E-19$ & 500 \\
\hline 10 & MKARANO & 500 & 1.31E.04 & 499.9993691 \\
\hline 11 & PR.TOK & 500 & $2.60 E-\infty 4$ & 459.55974 \\
\hline 12 & M. TAWAR & 500 & $1.17 E-64$ & 499.95938334 \\
\hline 13 & BEKASI & 500 & $2.58 E-19$ & 500 \\
\hline 14 & CAWANG & 500 & $1.776-13$ & 500 \\
\hline 15 & TrUCUT & 500 & $8.32 \mathrm{E}-01$ & 499.1678 \\
\hline 16 & BOCOR & 500 & $2.86 \mathrm{E}-05$ & 499.9999715 \\
\hline 17 & DEPOK & 500 & S.26E-18 & 500 \\
\hline 18 & CIBENONO & 500 & $7.84 E-14$ & 500 \\
\hline
\end{tabular}

10.21070/jeee-u.v\%vi\%i.1515

\begin{tabular}{|c|c|l|l|l|}
\hline 19 & TAMBUN & 500 & $6.03 E-14$ & 500 \\
\hline 20 & CIKALONG & 500 & $1.31 \mathrm{E}-09$ & 500 \\
\hline 21 & TASIK & 500 & $1.18 \mathrm{E}-08$ & 500 \\
\hline 22 & MATENGGENG & 500 & $1.42 \mathrm{E}-04$ & 499.999858 \\
\hline 23 & RAWALO & 500 & $1.25 \mathrm{E}-04$ & 499.9998748 \\
\hline 24 & PEDAN & 500 & $7.25 \mathrm{E}-14$ & 500 \\
\hline 25 & KEDIRI & 500 & $2.12 \mathrm{E}-09$ & 500 \\
\hline 26 & BANGIL & 500 & $7.82 \mathrm{E}-09$ & 500 \\
\hline 27 & PAITON & 500 & $3.37 \mathrm{E}-04$ & 499.9996631 \\
\hline 28 & JAWA1 & 500 & $8.01 \mathrm{E}-01$ & 499.1987 \\
\hline 29 & CIBATU B & 500 & $7.73 \mathrm{E}-09$ & 500 \\
\hline 30 & CIBATU & 500 & $1.72 \mathrm{E}-09$ & 500 \\
\hline 31 & DELTAMAS & 500 & $2.42 \mathrm{E}-05$ & 499.9999758 \\
\hline 32 & CIRATA & 500 & $1.14 \mathrm{E}-04$ & 499.9998865 \\
\hline 33 & SAGULING & 500 & $6.67 \mathrm{E}-01$ & $4.99 \mathrm{E}+02$ \\
\hline 34 & BANDUNG SEL & 500 & $6.19 \mathrm{E}-09$ & 500 \\
\hline 35 & U.BERUNG & 500 & $5.04 \mathrm{E}-13$ & 500 \\
\hline 36 & MANDIRANCAN & 500 & $5.58 \mathrm{E}-05$ & 499.9999442 \\
\hline 37 & CIREBON & 500 & $8.18 \mathrm{E}-01$ & 499.1824 \\
\hline 38 & JATENG & 500 & $6.14 \mathrm{E}-01$ & 499.3858 \\
\hline 39 & INDRAMAYU & 500 & $8.34 \mathrm{E}-01$ & 499.166 \\
\hline 40 & PEMALANG & 500 & $3.94 \mathrm{E}-09$ & 500 \\
\hline 41 & TJATI & 500 & $6.74 \mathrm{E}-04$ & 499.999326 \\
\hline 42 & UNGARAN & 500 & $4.57 \mathrm{E}-08$ & 500 \\
\hline 43 & AMPEL & 500 & $2.47 \mathrm{E}-09$ & 500 \\
\hline 44 & NGIMBANG & 500 & $4.58 \mathrm{E}-12$ & 500 \\
\hline 45 & KRIAN & 500 & $1.32 \mathrm{E}-08$ & 500 \\
\hline 46 & GRATI & 500 & $1.46 \mathrm{E}-04$ & 499.9998537 \\
\hline 47 & SURABAYA SEL & 500 & $3.53 \mathrm{E}-09$ & 500 \\
\hline 48 & GRESIK & 500 & $1.83 \mathrm{E}-04$ & 499.999817 \\
\hline 49 & TANDES & 500 & $6.63 \mathrm{E}-09$ & 500 \\
\hline 50 & KAPAL & 500 & $6.10 \mathrm{E}-09$ & 500 \\
\hline & & & & \\
\hline
\end{tabular}

Tabel 3 diatas menunjukkan hasil pengujian loadflow pada sistem yang telah dipasang UPFC yang mana nilai dari UPFC juga sudah ditentukan yang paling optimal. Dimana nilai tersebut masih dalam batas toleransi yang diijinkan yaitu + $5 \%$ dan -

10\% sesuai dengan standar SPLN 1:1995 pasal 4.

Tabel 4 dibawah menunjuk kanhasil perbedaan ketika dipasang UPFC dan di tempatkan di Indramayu, Tpucut dan Cirebon sesudah dipasang UPFC dengan GA pada sistem interkoneksi Jawa Bali 500

$\mathrm{KV}$.

Tabel 4. Hasil Loadflow dan Rugi Daya setelah ada UPFC ditempatkan di Indramayu

\begin{tabular}{|l|c|c|c|}
\hline BUS & Vpos.seg & P(Mw) & Q(Mvar) \\
\hline BUS 1 & 0.0008599 & 7.924 & 3.876 \\
\hline BUS 2 & 0.0001937 & $2.51 \mathrm{E}-05$ & 0.0001215 \\
\hline BUS 3 & 0.845 & 130.7 & 721.4 \\
\hline BUS 4 & 0.802 & 130.7 & 1134 \\
\hline BUS 5 & $5.17 \mathrm{E}-05$ & 0.2979 & 0.07065 \\
\hline BUS 6 & $2.45 \mathrm{E}-19$ & $4.43 \mathrm{E}-10$ & $2.15 \mathrm{E}-10$ \\
\hline BUS 7 & $3.20 \mathrm{E}-09$ & $3.36 \mathrm{E}-18$ & $1.77 \mathrm{E}-18$ \\
\hline BUS 8 & $3.06 \mathrm{E}-09$ & $2.72 \mathrm{E}-10$ & $1.32 \mathrm{E}-10$ \\
\hline BUS 9 & $4.02 \mathrm{E}-19$ & $-1.47 \mathrm{E}-12$ & $5.99 \mathrm{E}-15$ \\
\hline BUS 10 & $1.31 \mathrm{E}-04$ & $8.16 \mathrm{E}-01$ & $3.95 \mathrm{E}-01$ \\
\hline BUS 11 & $2.60 \mathrm{E}-04$ & $2.12 \mathrm{E}+00$ & $1.03 \mathrm{E}+00$ \\
\hline BUS 12 & $1.17 \mathrm{E}-04$ & $1.25 \mathrm{E}+00$ & $5.87 \mathrm{E}-01$ \\
\hline BUS 13 & $2.58 \mathrm{E}-19$ & $-6.83 \mathrm{E}-15$ & $-9.43 \mathrm{E}-14$ \\
\hline BUS 14 & $1.77 \mathrm{E}-13$ & $-9.39 \mathrm{E}-25$ & $-1.23 \mathrm{E}-22$ \\
\hline BUS 15 & $8.32 \mathrm{E}-01$ & $9.01 \mathrm{E}+01$ & $6.51 \mathrm{E}+02$ \\
\hline
\end{tabular}


TIF

\begin{tabular}{|l|c|c|c|}
\hline BUS 16 & $2.86 \mathrm{E}-05$ & $-2.05 \mathrm{E}-02$ & $-9.93 \mathrm{E}-03$ \\
\hline BUS 17 & $5.26 \mathrm{E}-18$ & $1.95 \mathrm{E}-10$ & $3.20 \mathrm{E}-10$ \\
\hline BUS 18 & $7.84 \mathrm{E}-14$ & $-3.26 \mathrm{E}-06$ & $-3.03 \mathrm{E}-06$ \\
\hline BUS 19 & $6.03 \mathrm{E}-14$ & $4.56 \mathrm{E}-10$ & $-6.39 \mathrm{E}-10$ \\
\hline BUS 20 & $1.31 \mathrm{E}-09$ & $-1.85 \mathrm{E}-10$ & $-1.27 \mathrm{E}-11$ \\
\hline BUS 21 & $1.18 \mathrm{E}-08$ & $-4.72 \mathrm{E}-09$ & $-2.29 \mathrm{E}-09$ \\
\hline BUS 22 & $1.42 \mathrm{E}-04$ & $5.13 \mathrm{E}-01$ & $2.48 \mathrm{E}-01$ \\
\hline BUS 23 & $1.25 \mathrm{E}-04$ & $1.49 \mathrm{E}+00$ & $7.23 \mathrm{E}-01$ \\
\hline BUS 24 & $7.25 \mathrm{E}-14$ & $7.89 \mathrm{E}-07$ & $1.09 \mathrm{E}-05$ \\
\hline BUS 25 & $2.12 \mathrm{E}-09$ & $1.44 \mathrm{E}-14$ & $-3.60 \mathrm{E}-14$ \\
\hline BUS 26 & $7.82 \mathrm{E}-09$ & $-4.33 \mathrm{E}-09$ & $-2.10 \mathrm{E}-09$ \\
\hline BUS 27 & $3.37 \mathrm{E}-04$ & $6.76 \mathrm{E}+00$ & $3.27 \mathrm{E}+00$ \\
\hline BUS 28 & $8.01 \mathrm{E}-01$ & $1.67 \mathrm{E}+02$ & $1.21 \mathrm{E}+03$ \\
\hline BUS 29 & $7.73 \mathrm{E}-09$ & $2.85 \mathrm{E}-09$ & $1.38 \mathrm{E}-09$ \\
\hline BUS 30 & $1.72 \mathrm{E}-09$ & $-2.42 \mathrm{E}-14$ & $-4.36 \mathrm{E}-14$ \\
\hline BUS 31 & $2.42 \mathrm{E}-05$ & $-1.32 \mathrm{E}-07$ & $-1.83 \mathrm{E}-06$ \\
\hline BUS 32 & $1.14 \mathrm{E}-04$ & $5.02 \mathrm{E}-01$ & $8.79 \mathrm{E}-02$ \\
\hline BUS 33 & $6.67 \mathrm{E}-01$ & $3.47 \mathrm{E}+02$ & $2.51 \mathrm{E}+03$ \\
\hline BUS 34 & $6.19 \mathrm{E}-09$ & $-4.69 \mathrm{E}-07$ & $-6.46 \mathrm{E}-06$ \\
\hline BUS 35 & $5.04 \mathrm{E}-13$ & $4.75 \mathrm{E}-10$ & $2.30 \mathrm{E}-10$ \\
\hline BUS 36 & $5.58 \mathrm{E}-05$ & $-7.42 \mathrm{E}-02$ & $-4.63 \mathrm{E}-02$ \\
\hline BUS 37 & $8.18 \mathrm{E}-01$ & $1.74 \mathrm{E}+02$ & $1.26 \mathrm{E}+03$ \\
\hline BUS 38 & $6.14 \mathrm{E}-01$ & $1.73 \mathrm{E}+02$ & $1.25 \mathrm{E}+03$ \\
\hline BUS 39 & $8.34 \mathrm{E}-01$ & $1.44 \mathrm{E}+02$ & $9.59 \mathrm{E}+02$ \\
\hline BUS 40 & $3.94 \mathrm{E}-09$ & $5.50 \mathrm{E}-11$ & $2.93 \mathrm{E}-10$ \\
\hline BUS 41 & $6.74 \mathrm{E}-04$ & $1.08 \mathrm{E}+01$ & $5.24 \mathrm{E}+00$ \\
\hline BUS 42 & $4.57 \mathrm{E}-08$ & $-1.77 \mathrm{E}-09$ & $-1.90 \mathrm{E}-11$ \\
\hline \hline BUS 43 & $2.47 \mathrm{E}-09$ & $-2.53 \mathrm{E}-13$ & $2.28 \mathrm{E}-13$ \\
\hline BUS 44 & $4.58 \mathrm{E}-12$ & $5.29 \mathrm{E}-16$ & $3.84 \mathrm{E}-16$ \\
\hline BUS 45 & $1.32 \mathrm{E}-08$ & $-3.91 \mathrm{E}-14$ & $-5.38 \mathrm{E}-13$ \\
\hline BUS 46 & $1.46 \mathrm{E}-04$ & $7.02 \mathrm{E}-01$ & $3.40 \mathrm{E}-01$ \\
\hline BUS 47 & $3.53 \mathrm{E}-09$ & $-8.92 \mathrm{E}-10$ & $-4.32 \mathrm{E}-10$ \\
\hline BUS 48 & $1.83 \mathrm{E}-04$ & 2.232 & 1.081 \\
\hline BUS 49 & $6.63 \mathrm{E}-09$ & $-2.09 \mathrm{E}-09$ & $-1.01 \mathrm{E}-09$ \\
\hline BUS 50 & $6.10 \mathrm{E}-09$ & $1.93 \mathrm{E}-09$ & $9.35 \mathrm{E}-10$ \\
\hline Total & 6.216842356 & 1391.458892 & 9695.593207 \\
\hline Presentase & kemampuan UPFC Meminimalisasi rugi daya & \\
\hline & $8 \%$ & $13 \%$ & $14 \%$ \\
\hline & & & \\
\hline
\end{tabular}

Tabel 5. HasilLoadflowdan Rugi Daya setelah adaUPFC ditempatkan di Tpucut.

\begin{tabular}{|c|c|c|c|}
\hline BUS & Vposseg & $P(M w)$ & $Q$ (Mvar) \\
\hline BUS 1 & 0.0008598 & 7.4 & 4.803 \\
\hline BUS 2 & 0.0003322 & $.855 E .06$ & 0.0003396 \\
\hline BUS 3 & 0.81 & 168.5 & 1217 \\
\hline BUS 4 & 0.8125 & 175.4 & 1230 \\
\hline BUS 5 & $5.82 \mathrm{E}-05$ & 0.3149 & 0.1406 \\
\hline BUS 6 & 1.50 - 19 & $5.628-10$ & $2726-10$ \\
\hline BUS 7 & $1.96 \mathrm{E}-23$ & $4.27 \mathrm{E}-18$ & $2.24 f-18$ \\
\hline BUS 8 & $3.44 \mathrm{E}-09$ & $3.45 E-10$ & $1.67 \mathrm{E}-10$ \\
\hline BUS9 & $4.94 E-20$ & $2.906-15$ & $8.286-15$ \\
\hline BUS 10 & 1.31E- $-\infty$ & $8.16 E-01$ & $3.956-01$ \\
\hline BUS 11 & $2.60 \mathrm{E} \cdot 04$ & $2.12 \mathrm{E}+00$ & $1.03 E+00$ \\
\hline BUS 12 & $1.17 \mathrm{E}-04$ & $1.25 E+00$ & $5.870-01$ \\
\hline BUS 13 & $1.20 \mathrm{E}-19$ & $.6 .83 E-15$ & $-9.436: 14$ \\
\hline BUS 14 & $1.77 E-19$ & $-4.85 E-23$ & $-1.456-22$ \\
\hline BUS 15 & $8.36 E-01$ & $9.80 \mathrm{E}+01$ & $6.41 E+02$ \\
\hline BUS 16 & $3.24 \mathrm{E}-05$ & $.2 .64 E-02$ & $-1.286-02$ \\
\hline BUS 17 & $5.266-18$ & $3.67 E-11$ & $-1.366-10$ \\
\hline BUS 18 & $7.84 E-14$ & $1.41 \mathrm{E}-06$ & $-9.206-05$ \\
\hline BUS 19 & $6.03 E-69$ & $4.566-10$ & $-6.356-10$ \\
\hline BUS 20 & 4.64E- 10 & $-2.44 E-11$ & $-1.2)[-11$ \\
\hline BUS 21 & $1.18 \mathrm{E} \cdot 03$ & $-4.72 \mathrm{E} \cdot 09$ & $-2.296-09$ \\
\hline BUS 22 & $1.42 \mathrm{E}-04$ & 5.13E-01 & $2.435-01$ \\
\hline BUS 23 & $1.25 E-\infty 4$ & $1.49 \mathrm{E}+00$ & $7.236-01$ \\
\hline BUS 24 & $7.25 E \cdot 14$ & $7.89 \mathrm{E} \cdot 07$ & 1.09E.05 \\
\hline BUS 25 & $2.12 \mathrm{E}-09$ & $1.44 E-14$ & $-3.606-14$ \\
\hline BUS 26 & $7.82 \mathrm{E}-09$ & $-4.33 \mathrm{E}-09$ & $-2.106-09$ \\
\hline BUS 27 & $3.37 \mathrm{E} \cdot 04$ & $6.76 E+00$ & $3.27 E+00$ \\
\hline BUS 28 & $8.01 \mathrm{E}-01$ & $1.67 \mathrm{E}+02$ & 1.21E +03 \\
\hline BUS 29 & $7.73 E-69$ & 2.85E-09 & 1.395-09 \\
\hline BUS 30 & $2.13 E-\infty 9$ & $4.90 E-14$ & $-2.5 \operatorname{stc}-14$ \\
\hline BUS 31 & $2.996-05$ & $-2.011-07$ & $-2.786-06$ \\
\hline
\end{tabular}

\begin{tabular}{|c|c|c|c|}
\hline BUS 32 & $1.14 \mathrm{E}-04$ & $5.02 \mathrm{E}-01$ & $8.79 \mathrm{E}-02$ \\
\hline BUS 33 & $6.67 \mathrm{E}-01$ & $3.47 E+02$ & $2.51 E+03$ \\
\hline BUS 34 & $6.19 \mathrm{E}-09$ & $-4.69 \mathrm{E}-07$ & $-6.46 \mathrm{E}-06$ \\
\hline BUS 35 & $5.04 \mathrm{E}-13$ & $4.75 \mathrm{E}-10$ & $2.30 \mathrm{E}-10$ \\
\hline BUS 36 & $5.58 \mathrm{E}-05$ & $-7.42 E-02$ & $-4.63 \mathrm{E}-02$ \\
\hline BUS 37 & $8.18 \mathrm{E}-01$ & $1.74 \mathrm{E}+02$ & $1.26 \mathrm{E}+03$ \\
\hline BUS 38 & $8.14 \mathrm{E}-01$ & $1.73 \mathrm{E}+02$ & $1.25 \mathrm{E}+03$ \\
\hline BUS 39 & $8.25 \mathrm{E}-01$ & $1.77 \mathrm{E}+02$ & $1.28 \mathrm{E}+03$ \\
\hline BUS 40 & $4.83 \mathrm{E}-09$ & $4.50 \mathrm{E}-10$ & 1.07E-11 \\
\hline BUS 41 & $6.74 \mathrm{E}-04$ & $1.08 \mathrm{E}+01$ & $5.24 E+00$ \\
\hline BUS 42 & $4.57 \mathrm{E}-08$ & $-1.77 E-09$ & $-1.90 \mathrm{E}-11$ \\
\hline BUS 43 & $2.47 \mathrm{E}-09$ & $-2.53 E-13$ & $2.28 \mathrm{E}-13$ \\
\hline BUS 44 & $4.58 \mathrm{E}-12$ & $5.29 \mathrm{E}-16$ & $3.84 \mathrm{E}-16$ \\
\hline BUS 45 & $1.32 \mathrm{E}-08$ & $-3.91 \mathrm{E}-14$ & $-5.38 \mathrm{E}-13$ \\
\hline BUS 46 & $1.46 \mathrm{E}-04$ & $7.02 \mathrm{E}-01$ & $3.40 \mathrm{E}-01$ \\
\hline BUS 47 & $3.53 \mathrm{E}-09$ & $-8.92 \mathrm{E}-10$ & $-4.32 \mathrm{E}-10$ \\
\hline BUS 48 & $1.83 \mathrm{E}-04$ & 2.232 & 1.081 \\
\hline BUS 49 & $6.63 \mathrm{E}-09$ & $-2.09 E-09$ & $-1.01 \mathrm{E}-09$ \\
\hline BUS 50 & $1.22 \mathrm{E}-08$ & $7.72 \mathrm{E}-09$ & $3.74 \mathrm{E}-09$ \\
\hline Total & 6.387696786 & 1514.815953 & 10598.78754 \\
\hline \multicolumn{4}{|c|}{ Presentase kemampuan UPFC Meminimalisasi rugi daya } \\
\hline & $6 \%$ & $5 \%$ & $5 \%$ \\
\hline
\end{tabular}

Tabel 6. Hasil Loadflow dan Rugi Daya setelah ada UPFC ditempatkan di Cirebon

\begin{tabular}{|c|c|c|c|}
\hline BUS & Vpos.seg & P(Mw) & Q(Mvar) \\
\hline BUS 1 & 0.0008598 & 7.4 & 4.803 \\
\hline BUS 2 & 0.0003426 & $7.78 \mathrm{E}-05$ & 0.0003334 \\
\hline BUS 3 & 0.81 & 168.5 & 1217 \\
\hline BUS 4 & 0.8125 & 175.4 & 1230 \\
\hline BUS 5 & $5.82 \mathrm{E}-05$ & 0.3149 & 0.1406 \\
\hline BUS 6 & $1.50 \mathrm{E}-19$ & $5.62 \mathrm{E}-10$ & $2.72 \mathrm{E}-10$ \\
\hline BUS 7 & $1.96 \mathrm{E}-23$ & $4.27 \mathrm{E}-18$ & $2.24 \mathrm{E}-18$ \\
\hline BUS 8 & $3.44 \mathrm{E}-09$ & $3.45 \mathrm{E}-10$ & $1.67 \mathrm{E}-10$ \\
\hline BUS 9 & $4.94 \mathrm{E}-20$ & $2.90 \mathrm{E}-15$ & $8.29 \mathrm{E}-15$ \\
\hline BUS 10 & $1.31 \mathrm{E}-04$ & $8.16 \mathrm{E}-01$ & $3.95 \mathrm{E}-01$ \\
\hline BUS 11 & $2.60 \mathrm{E}-04$ & $2.12 \mathrm{E}+00$ & $1.03 \mathrm{E}+00$ \\
\hline BUS 12 & $1.17 \mathrm{E}-04$ & $1.25 \mathrm{E}+00$ & $5.87 \mathrm{E}-01$ \\
\hline BUS 13 & $1.20 \mathrm{E}-19$ & $-6.83 \mathrm{E}-15$ & $-9.43 \mathrm{E}-14$ \\
\hline BUS 14 & $1.77 \mathrm{E}-13$ & $-4.85 \mathrm{E}-23$ & $-1.45 \mathrm{E}-22$ \\
\hline BUS 15 & $8.22 \mathrm{E}-01$ & $1.76 \mathrm{E}+02$ & $1.27 \mathrm{E}+03$ \\
\hline BUS 16 & $5.64 \mathrm{E}-05$ & $-7.99 \mathrm{E}-02$ & $-3.87 \mathrm{E}-02$ \\
\hline BUS 17 & $5.26 \mathrm{E}-18$ & $1.04 \mathrm{E}-09$ & $5.09 \mathrm{E}-10$ \\
\hline BUS 18 & $7.84 \mathrm{E}-14$ & $7.70 \mathrm{E}-08$ & $1.93 \mathrm{E}-06$ \\
\hline BUS 19 & $6.03 \mathrm{E}-09$ & $4.56 \mathrm{E}-10$ & $-6.39 \mathrm{E}-10$ \\
\hline BUS 20 & $2.01 \mathrm{E}-09$ & $-2.58 \mathrm{E}-10$ & $-1.29 \mathrm{E}-06$ \\
\hline BUS 21 & $1.18 \mathrm{E}-08$ & $-4.72 \mathrm{E}-09$ & $-2.29 \mathrm{E}-09$ \\
\hline BUS 22 & $1.42 \mathrm{E}-04$ & $5.13 \mathrm{E}-01$ & $2.48 \mathrm{E}-01$ \\
\hline BUS 23 & $1.25 \mathrm{E}-04$ & $1.49 \mathrm{E}+00$ & $7.23 \mathrm{E}-01$ \\
\hline BUS 24 & $7.25 \mathrm{E}-14$ & $7.89 \mathrm{E}-07$ & $1.09 \mathrm{E}-05$ \\
\hline BUS 25 & $2.12 \mathrm{E}-09$ & $1.44 \mathrm{E}-14$ & $-3.60 \mathrm{E}-14$ \\
\hline BUS 26 & $7.82 \mathrm{E}-09$ & $-4.33 \mathrm{E}-09$ & $-2.10 \mathrm{E}-09$ \\
\hline BUS 27 & $3.37 \mathrm{E}-04$ & $6.76 \mathrm{E}+00$ & $3.27 \mathrm{E}+00$ \\
\hline BUS 28 & $8.01 \mathrm{E}-01$ & $1.67 \mathrm{E}+02$ & $1.21 \mathrm{E}+03$ \\
\hline BUS 29 & $7.73 \mathrm{E}-09$ & $2.85 \mathrm{E}-09$ & $1.38 \mathrm{E}-09$ \\
\hline BUS 30 & $2.13 \mathrm{E}-09$ & $4.90 \mathrm{E}-14$ & $-2.58 \mathrm{E}-14$ \\
\hline BUS 31 & $2.99 \mathrm{E}-05$ & $-2.01 \mathrm{E}-07$ & $-2.78 \mathrm{E}-06$ \\
\hline BUS 32 & $1.14 \mathrm{E}-04$ & $5.02 \mathrm{E}-01$ & $8.79 \mathrm{E}-02$ \\
\hline BUS 33 & $6.67 \mathrm{E}-01$ & $3.47 \mathrm{E}+02$ & $2.51 \mathrm{E}+03$ \\
\hline BUS 34 & $6.19 \mathrm{E}-09$ & $-4.69 \mathrm{E}-07$ & $-6.46 \mathrm{E}-06$ \\
\hline BUS 35 & $5.04 \mathrm{E}-13$ & $4.75 \mathrm{E}-10$ & $2.30 \mathrm{E}-10$ \\
\hline BUS 36 & $3.84 \mathrm{E}-05$ & $-3.51 \mathrm{E}-02$ & $-2.19 \mathrm{E}-02$ \\
\hline BUS 37 & $8.37 \mathrm{E}-01$ & $1.19 \mathrm{E}+02$ & $7.86 \mathrm{E}+02$ \\
\hline BUS 38 & $8.14 \mathrm{E}-01$ & $1.73 \mathrm{E}+02$ & $1.25 \mathrm{E}+03$ \\
\hline BUS 39 & $8.25 \mathrm{E}-01$ & $1.77 \mathrm{E}+02$ & $1.28 \mathrm{E}+03$ \\
\hline BUS 40 & $2.11 \mathrm{E}-09$ & $1.74 \mathrm{E}-11$ & $1.96 \mathrm{E}-10$ \\
\hline BUS 41 & $6.74 \mathrm{E}-04$ & $1.08 \mathrm{E}+01$ & $5.24 \mathrm{E}+00$ \\
\hline BUS 42 & $4.57 \mathrm{E}-08$ & $-9.98 \mathrm{E}-13$ & $-1.90 \mathrm{E}-11$ \\
\hline BUS 43 & $2.47 \mathrm{E}-09$ & $-2.53 \mathrm{E}-13$ & $2.28 \mathrm{E}-13$ \\
\hline & & & \\
\hline
\end{tabular}




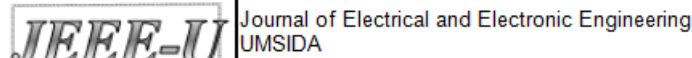 SSN 2460-9250 (print), ISSN 2540-8658 (online) Vol. 2, No. 1, April 2018}

\begin{tabular}{|c|c|c|c|}
\hline BUS 44 & $4.58 \mathrm{E}-12$ & $5.29 \mathrm{E}-16$ & $3.84 \mathrm{E}-16$ \\
\hline BUS 45 & $1.32 \mathrm{E}-08$ & $-3.91 \mathrm{E}-14$ & $-5.38 \mathrm{E}-13$ \\
\hline BUS 46 & $1.46 \mathrm{E}-04$ & $7.02 \mathrm{E}-01$ & $3.40 \mathrm{E}-01$ \\
\hline BUS 47 & $3.53 \mathrm{E}-09$ & $-8.92 \mathrm{E}-10$ & $-4.32 \mathrm{E}-10$ \\
\hline BUS 48 & $1.83 \mathrm{E}-04$ & 2.232 & 1.081 \\
\hline BUS 49 & $6.63 \mathrm{E}-09$ & $-2.09 \mathrm{E}-09$ & $-1.01 \mathrm{E}-09$ \\
\hline BUS 50 & $1.22 \mathrm{E}-08$ & $7.72 \mathrm{E}-09$ & $3.74 \mathrm{E}-09$ \\
\hline Total & 6.392513735 & 1537.391648 & 10755.88608 \\
\hline Presentase kemampuan UPFC meminimalisasi rugi daya \\
\hline \multicolumn{4}{|c|}{$6 \%$} \\
\hline
\end{tabular}

Dilihat dari ketiga table diatas, secara umum tegangan pada sistem interkoneksi Jawa Bali $500 \mathrm{kV}$ mengalami perubahan setelah dipasang UPFC dengan penempatan yang optimal menggunakan GA. Sedangkan pada bus yang lainnya mengalami perubahan sehingga tegangan menjadi stabil dimana nilai tersebut masih dalam batas toleransi yang diijinkan yaitu $+5 \%$ dan $-10 \%$ sesuai dengan standar SPLN 1:1995 pasal 4. Penginjeksian besaran dan sudut fasa tegangan injeksi seri (Vpq dan

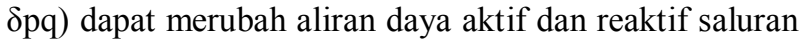
dari aliran daya dasarnya. Perubahan ini terjadi oleh karena variasi tegangan injeksi seri yang ditransformasikan ke dalam penginjeksian daya akan merubah besaran dan sudut fasa tegangan pada kedua ujung saluran yang mengakibatkan arus seri saluran juga berubah. Perubahan arus saluran selanjutnya akan merubah aliran daya aktif dan reaktif saluran. Pengoptimalan aliran daya saluran dari variasi aliran daya aktif menghasilkan variasi penginjeksian besaran dan sudut fase tegangan seri sehingga dapat meminimalisasi rugi daya aktif total system transmisi Sehingga pada penelitian ini pemasangan UPFC dengan penempatan yang optimal menggunakan metode GA.

\subsubsection{Analisis Sistem}

Secara umum tegangan pada sistem interkoneksi JawaBali $500 \mathrm{kV}$ mengalami perubahan setelah dipasang UPFC dengan kapasitas yang optimal menggunakan GA. Ada beberapa bus yang tidak mengalami perubahan dikarenakan tegangan sudah mencapai kestabilan yaitu $500 \mathrm{KV}$, akan tetapi beberapa bus yang lainnya mengalami perubahan sehingga tegangan menjadi stabil dimana nilai tersebut masih dalam batas toleransi yang diijinkan yaitu $+5 \%$ dan $-10 \%$ sesuai dengan standar SPLN 1:1995 pasal 4Pada sistem Jawa Bali (Jali) $500 \mathrm{kV}$ yang dianalisis dengan metode Algoritma Genetika, hasil darinilai
UPFC yang optimalDaya Reaktif yang diinjeksikan pada sistem untuk bus 39 sebesar 9695.593207 MVar, bus 15 sebesar 10598.78754 MVar, dan pada bus 37 sebesar 10755.88608 MVar.Dengan metode Algoritma Genetika, didapat pengoptimalan nilai UPFC pada bus sensitif sebagai berikut:
a. Bus 39= 1562 MVar dengan tegangan0.912 $\mathrm{KV}$.
b. Bus $15=1515$ MVar dengan tegangan $0.8981 \mathrm{KV}$.
c. Bus37 = 1477 MVar dengan tegangan $0.8867 \mathrm{kV}$.

Total rugi - rugi daya saluran pada sistem sebelum dipasang UPFC adalah

1815.7758 MW, sedangkan total rugi - rugi daya saluran pada sistem sesudah dipasang UPFC dengan GA adalah 1537.391648MW. Sehingga secara keseluruhan rugi rugi daya saluran pada sistem interkoneksi JawaBali 500 $\mathrm{kV}$ mengalami penurunan setelah dipasang UPFC dengan kapasitas yang optimal menggunakan GA.

Berdasarkan hasil diatas, dengan demikian sistem dapat dikatakan stabil dimana nilai tersebut masih dalam batas toleransi yang diijinkan yaitu $+5 \%$ dan 10\% sesuai dengan standar SPLN 1:1995 pasal 4.

\section{KESIMPULAN}

Dengan pencarian nilai penempatan UPFC menggunakan Algoritma Genetika dapat diketahui bahwa nilai yang belum di pasang UPFC untuk bus 39 sebesar 1562 MVar, bus 13 sebesar 1515 MVar, dan bus 37 sebesar 1477 MVar.

Daya Reaktif yang diinjeksikan pada sistem untuk bus 39 sebesar 9695.593207 MVar, bus 15 sebesar 10598.78754 MVar, dan pada bus 37 sebesar 10755.88608 MVar.

Tegangan yang dihasilkan setelah ditentukannya penempatan UPFC yang optimal yaitu pada bus 39 menjadi $6.368931148 \mathrm{kV}$, bus 15 menjadi $6.38769687 \mathrm{kV}$, dan bus 37 menjadi $6.392513735 \mathrm{kV}$. Total rugi - rugi daya saluran pada sistem sebelum dipasang UPFC adalah 1815.775809 MW, sedangkan total rugi - rugi daya saluran pada sistem sesudah dipasang UPFC dengan GA adalah 1537.391648 MW. Dengan begitu sistem dapat dikatakan stabil dimana nilai tersebut masih dalam batas toleransi yang diijinkan yaitu $+5 \%$ dan $-10 \%$ sesuai dengan standar SPLN 1:1995 pasal 4. 


\section{REFERENSI}

1. Carlos RS1, Hamzah Berahim2 dan Soedjatmiko.Seminar Nasional Teknik Menggunakan Pengendalian Aliran Daya Terpadu.

2. Rusejla Sadikovic,Internal Report,Power Flow Control With UPFC.

3. Saadat,Hadi.1999.Power System Analysis.McGrawHill.

4. Lesnanto multa putranto, Restu Prima Andani pengaruh penempatan upfc terhadap kestabilan tegangan sistem tenaga listrik, UGM, 2013.

5. Anwar, S. 2012. Optimasi Penempatan SVC untuk Memperbaiki Profil Tegangan dengan Menggunakan Algoritma Genetika. Jurnal Elektro ELTEK. Vol. 3, no. 1. Malang : Universitas Brawijaya. 